dünnten Zustande dieses Salz, allein, wie die erwähnten qualitativen und quantitativen Versuche beweisen, geschieht dies von ihr in geringerem Maasse, als von den übrigen Säuren.

\title{
XXI.
}

Bemerkungen über die Darstellung von Traubenzucker im Zustande chemischer Reinheit. Von

\section{Emil Siegle.}

Als Doctor Bertagnini zu gewissen Versuchen ganz reinen Traubenzucker bedurfte, versuchte ich, ihm dieses Produkt zu verschaffen, indem ich auf gewöhnliche Weise Stärkemehl in Zucker überführte. Aus dem bei dieser Operation erhaltenen. süssen Syrup war es mir jedoch nicht möglich, krystallisirten Traubenzucker auszuziehen, obgleich ich ihn verschiedenen alkoholischen Behandlungen unterwarf, und erst nach Verfluss einiger Monate hatte dieser Syrup blumenkohlartige Krystalle abgesetzt, welche sehr dunkel und mit Alkohol nur mühsam von der sie umgebenden klebrigen Materie $\mathrm{zu}$ befreien waren. Selbst aus dem von Frankreich kommenden Traubenzucker (welchen man dort im Handel findet, bei uns aber nur schwierig bekommt) gelang es mir nicht, mit gleicher Behandlung ein Produkt von der geforderten Reinheit erhalten zu können.

Zur Erreichung meines Vorhabens habe ich nun versucht, ob es nicht möglich wäre, auf eine einfuche Art den im Honige befindlichen krystallisirten Traubenzucker, von dem ihn begleitenden unkrystallisirbaren Zucker zu trennen, und habe meinen Zweck erreicht, ohne zu dem gewöhnlichen Hülfsmittel der alkoholischen Behandlungen, welche im Allgemeinen nicht sehr befriedigende Resultate liefern, greifen zu müssen.

$\mathrm{Zu}$ diesem Behufe wählte ich diejenige Qualität des im Handel befindlichen Honigs, der eine möglichst grosse Anzahl von krystallinischen Körnern enthielt und strich 
ihn in dünnen Lagen auf sehr trockene poröse Backsteine auf. Schon nach Verfluss weniger Stunden beginnt der Honig heller zu werden, bis er nach zwei bis drei Tagen in eine weisse, aus kleinen glänzenden Krystallen bestehende Masse umgewandelt ist, vollständig befreit von der braunen Flüssigkeit, welche sie zuvor einschloss. Wenn man das Produkt sammelt, auf dem Wasserbade in etwa seinem achtfachen Gewichte gewöhnlichen Alkohols löst und die Lösung noch warm filtrirt, so krystallisirt der Zucker in blendend weissen blumenkohlähnlichen Krystallen. Wäre die alkoholische Lösung gefärbt, so genügt es, um ihr alle Farbe zu nehmen, wenn man sie mit einer geringen Menge Thierkohle behandelt. Wird die krystallinische Masse einige Stunden über Schwefelsäure gesetzt, so verliert sie noch Spuren von Alkohol und liefert auf diese Weise ein völlig geruchloses Produkt, welches sich leicht pulverisiren lässt und Traubenzucker auf dem höchsten Grad der Reinheit darstellt. Der gewöhnliche Honig liefert auf diesem Wege etwa 1/4 seines Gewichts reinen Zucker.

Endlich wenn man auf dem Wasserbade eine wässrige, äquivalente Mengen von diesem Zucker und von Chlornatrium enthaltende Lösung verdampft, so erhält man sofort die bekannte Verbindung von $\mathrm{C}_{24} \mathrm{H}_{24} \mathrm{O}_{24}, \mathrm{NaCh}, 2 \mathrm{IIO}$ in schönen, weissen, transparanten Krystallen, während man sonst diese Verbindung mit nicht ganz reinem Zucker erst nach längerer Zeit erbält.

\section{XXII. \\ Beiträge zur Pflanzenchemie.$$
\text { Von }
$$

Dr. E. Witting jun.

Die folgenden Analysen stellte ich in der Absicht an, durch eine grössere Anzahl genauer Untersuchungen der unorganischen Bestandtheile von Pflanzen, welche unter natürlichen und nicht durch die Cultur bedingten Verhält- 